\title{
The Effectiveness Of Standard Operating Procedures (SOP) in Licensing Services in the Capital Investmen and Integrated Services
}

\author{
Enza Resdiana ${ }^{1}$ and Endang Widyastuti ${ }^{2}$ \\ \{enza.resdiana@gmail.com ${ }^{1}$, endangwidyastuti_fe@yahoo.co.id ${ }^{2}$ \} \\ ${ }^{1}$ Faculty of Social and Politic Science, Wiraraja University \\ ${ }^{2}$ Faculty of Economic and Business, Wiraraja University
}

\begin{abstract}
This research was motivated by the importance of Standard Operating Procedures in the services of the Sumenep Regency Investment and Integrated Services Office. The existence of the Standard Operating Procedures in the Sumenep Regency Investment and Integrated One-Stop Service which should improve service to service users is not achieved by blowing negative issues in the community. This is a phenomenon that needs to be studied and researched more deeply so that a common point is found about the importance of the Standard Operating Procedures in service at the Integrated Licensing Service Agency of Sumenep Regency. This study uses qualitative research methods that explain the importance of the Standard Operating Procedures in the services of the Sumenep Regency Investment and Integrated One-Stop Service based on experiences and awareness that occur in several individuals. Search for and analyze the importance of Standard Operating Procedures in services at the Sumenep Regency Investment and Integrated Services Office. The researcher explored information and data in the field by interviewing the guide (guide) to informants, field observations with predetermined observation guidelines, and pre-determined field documentation. The results of this study are described through various information and findings data in the field during the research, on the importance of the Standard Operating Procedures in the services of the Sumenep Regency Investment and Integrated Services Office. Lack of readiness and lack of evaluation on Standard Operating Procedures make service not run optimally. Lack of transparency and clarity of procedures on standard operating procedures for service users causes distrust of service users to existing procedures.
\end{abstract}

Keywords. Standard Operating Procedures, services, Integrated Licensing Service Agency of Sumenep Regency

\section{Introduction}

Based on the mandate of the 1945 Constitution of the Republic of Indonesia, the regional government, which regulates and manages government affairs according to the principle of autonomy and co-administration, is directed at accelerating the realization of community welfare through improvement, service, empowerment, and community participation, as well as 
increasing regional competitiveness by taking into account the principles of democracy, equity, justice, privilege and specificity of a region in the system of the Republic of Indonesia.

In the implementation of regional autonomy, the government implemented decentralization and regional autonomy policies in Indonesia as stipulated in Law Number 32 of 2004 concerning Regional Government which stated that the government with various public organizations provided various ways and alternatives to achieve certain goals or objectives, so that fulfillment of people's wishes.

Furthermore, a public organization itself has an activity procedure that must be obeyed by every member of the organization. So to realize the same goal, each member of the organization is bound by certain procedures that must be followed and obeyed. This is what is often called that to carry out activities that are effective and efficient, organizations need standard operating procedures or commonly called standard operating procedures.

The same thing is also explained in Law No. 25 of 2009 concerning public services, that in the standard components of service to organizations at least include systems, mechanisms, and standard operating procedures. This means that after the standard arrangement of servants, the government with various organizations also compiled and determined standard operating procedures. In general, standard operating procedures are an overview of work steps (systems, mechanisms, and internal work procedures) that are needed in carrying out a task to achieve the objectives of government agencies.

Through the preparation and stipulation of the standard operating procedures, it can streamline service improvements. Because standard operating procedures are guidelines or references for carrying out work duties in accordance with the functions and tools of performance appraisal of government agencies based on technical, administrative and procedural indicators in accordance with work procedures, work procedures and work systems in the work unit concerned and creating commitments regarding what done by the work units of government agencies.

Standard operating procedures in public services are part of the activities of public organizations. As is well known, public organizations have a very broad dimension in the implementation of state life. From this broad dimension, public service is the aspect that most closely touches the community.

Public service is a benchmark of the most visible performance of the government. The public can directly assess the government's performance based on the quality of public services received, because the quality of public services is in the interests of many people and the impact is directly felt by the community from all walks of life, where success in building public service performance in a professional, effective, efficient and accountable manner will lift the government's positive image .

However, it is no longer a secret anymore that the implementation of services to the community in some ways has not gone as well as expected. This can be seen from the existence of complaints and complaints from the public, both delivered directly to service providers and through the mass media.

The poor public service is not new, the facts in the field still show a lot of this. The 2002 Governance and Decentralization Survey (GDS) in Dwiyanto, 2003.70 found three important problems that occur in the field of public service delivery, namely: First, the magnitude of service discrimination. Service delivery is still very much influenced by relationship relations, similarities in political, ethnic, and religious affiliations. This kind of phenomenon continues to 
flourish despite the enactment of Law Number 28 of 1999 concerning the Implementation of a Clean Country from Community Service Programs which expressly states the necessity for equality of services, not discrimination.

Second, there is no certainty about the cos The same goes for one of the Sumenep Regency Government Offices, namely the Sumenep Regency Investment and Integrated Services Office. Although using standard operating procedures as a guideline for the implementation of services, the fact in the field states that there are still many overlapping regulations, complicated procedures, high costs, lack of certainty in the period of completion, inadequate facilities and infrastructure and ineffective and inefficient performance of officers, is the biggest obstacle to licensing services faced by the community in Sumenep Regency. This phenomenon makes the problem itself, so the researcher took the title "Effectiveness of Standard Operating Procedures (Sop) in Licensing Services at the Sumenep Regency Investment and Integrated Services"

\section{Theory}

\subsection{Standard Operating Procedures in the Organization}

According to Tambunan (2013.6) Organizations are companies, corporations, firms, institutions, institutions, or parts contained within them (both in the private sector) that have operational and administrative functions that support interactions and transactions with other organizations. The organization is a container or tool that is very important and needed to achieve goals or objectives with clearly defined functions and activities.

Furthermore according to Tambunan $(2013,84)$ Standard operating procedures as part of an organization which is also a separate system within an organization. Standard operating procedures as a subsystem of an organizational system because the organization is a separate system, or it can also consider standard operating procedures as a system. Standard operating procedures will work to influence each other with the system.

According to Government Regulation Number 102 of 2000, standards are technical specifications or something standardized including procedures and methods arranged based on the consensus of all parties concerned about safety, security, health, environmental, scientific and technological developments, experience, current and future developments to obtain maximum benefits. and time of service. This uncertainty is often the cause of the emergence of KKN because service users tend to choose high-cost bribes to service providers to get certainty and quality of service. Third, the low level of public satisfaction with public services. This is a logical consequence of service discrimination and uncertainty.

People who are customers of public services, also have needs and expectations in the performance of professional public service providers. So what is now the task of the central government and regional governments is how to provide public services that can satisfy the public.

Furthermore, in the PERMEN PAN and RB No: 36 of 2012 concerning Technical Guidelines for Preparation, Determination, and Application of Service Standards, interpreting service standards is a benchmark used as a guideline for the implementation of services and references for evaluating service improvements as obligations and promises of organizers to the community in the context of service repairing, fast, easy, affordable, and measurable. 
According to Tambunan (2013.3) standard operating procedures are basically guidelines that contain standard operational procedures that exist within an organization that are used to ensure that every decision, step, or action, and use of processing facilities are carried out by people within an organization, it has been running effectively, consistently, standards and systematically

\subsection{Terms of Standard Operating Procedures}

Effective standard operating procedures requirements in Tambunan $(2013,86)$, namely: a. Effective (and efficient)

The word effective, according to the literal meaning is: according. Or in another sentence that is stated as: "do the right thing." Do something right. Or do something appropriate. The word efficient is written with the sentence: "do the thing right." the meaning contained in this sentence is to do something right. An understanding of effectiveness and efficiency also applies equally in the preparation and application of standard operating procedures. in every policy and procedure covered by standard operating procedures, effectiveness and efficiency must be achieved. Likewise in terms of implementing the procedure steps.

b. Consistent

Standard operating procedures must be applied consistently, both for the same thing in the same place or for the same for different places. To ensure consistency, internal controls must be applied, both in general and in detail per activity on a standard operating procedure.

c. Standards

Standards can be divided into two: namely procedural standards and understanding standards. Procedural standards are standards that are seen in procedures or procedure manuals. Procedural standards, namely that existing procedure statements (coverage) in the manual standard operating procedures, must be presented in a standard format. Other standards are the standard understanding of standard operating procedures. This standard should be an inherent part of procedural standards.

d. Systematic

Systematic characteristics related to the appearance and explanation of standard operating procedures. A standard operating procedure, like a guideline or guideline, must be carried out in a clean, orderly and predictable system, and based on measures of success, failure, and clear and reliable risks accounted for Systematic can be interpreted neatly and regularly, which is an absolute requirement of an effective guideline to be used by an organization.

\subsection{Public Services}

According to Lukman $(1999,18)$ argues, service is an activity or sequence of activities that occur indirect interaction between someone and another person or machine physically and provides customer satisfaction. The term public comes from public English which means public, society, country. The public word has been accepted as Baku Indonesian becoming public, which means public, people, and people. Therefore public servants are interpreted as every activity carried out by the government towards many people who have every activity that is 
profitable in a group or entity, and offers satisfaction even though the results are not physically bound to a product.

\section{$3 \quad$ Method}

This research was conducted with descriptive qualitative methods in three ways, namely through in-depth interviews to explore data, field observations and documentation needed for the research subjects. which became the focus of research on the importance of the Standard Operating Procedures in Licensing Services at the Integrated Investment and Licensing Service of Sumenep Regency, including: effective and efficient, consistent, standard and systematic

Meanwhile, the subject and object of the research were the Sumenep district Investment and Integrated Services Office. Data collection techniques or data sources collected by researchers according to Indriantoro and Supomo $(1999,146)$ consist of primary data through the results of in-depth interviews and direct observations conducted by researchers. In addition to collecting data obtained from the results of documentation and literature (secondary data)

Data analysis techniques, carried out by researchers According to Miles and Huberman $(1992,18)$ there are three lines of qualitative data analysis, namely: first, data reduction which is the process of selecting, convergence, attention to simplification of data from all data obtained. Second, the presentation of data is done by unanimous statements or conclusions about a problem examined in a descriptive and interpretative language. (Sugiyono, 2016)

The tools/instruments in this study are following the focus of the research, namely the researchers themselves who have been assisted by using interview guidance tools and documentation facilities, places, and events.

\section{Results}

The Sumenep Regency Investment and Integrated One-Stop Service was formed based on the Sumenep District Regulation concerning the Organization and Work Procedure of the Integrated Licensing Service Agency of Sumenep Regency which is located as a supporting element of the Regional Government. The One-Stop Investment Service and Integrated Services are part of the Regional Organization (OPD) which is located under and is responsible to the Regent through the Regional Secretary.

Furthermore, which will be discussed in the discussion, can not be separated from the focus of research on standard operating procedures in services, namely: effectiveness (and efficient), consistent, standard and systematic.

\subsection{Effective (and efficient)}

Efficiency and effectiveness can be achieved when the One-Stop Investment Service and Integrated Service staff perform tasks and services based on standard operating procedures. Effectiveness and efficiency here are in the form of accuracy and accuracy of services provided to service users. Effective and efficiency is one of the principles contained in the standard operating procedures themselves. As with the theory of SESPANAS LAN in Faozan (2009.9) which states the principles in standard operating procedures including ease and clarity, 
efficiency and effectiveness, harmony, measurement, dynamic, user-oriented (those who are served), legal compliance, and legal certainty.

Employees of Sumenep Regency's Investment and Integrated One-Stop Service who are always guided by standard operating procedures provide their advantages in carrying out their activities, those who are always based on standard operating procedures will be easy when providing services to the community. This is following Tambunan's theory $(2013,106)$ which states the role and benefits of standard operating procedures as guidelines in an organization are organizing process to facilitate data analysis and conclusions. Third, concluding, namely making

a. Become a policy guideline which is the basis for all organizational activities, operationally and administratively.

b. Become a guideline for organizational activities, both operationally and administratively.

c. Become a guideline to validate the steps of activities in the organization.

d. Become a guideline regarding the use of forms, documents, forms, and reports used in organizational activities.

e. Become a guideline for evaluating the effectiveness of organizational activities.

f. Become a guideline for integrating organizational activities, to help achieve organizational goals.

Employees do not convey everything in the standard operating procedures to service users, so that service users do not know for certain the procedures of the time, cost, and completion, then service users only follow everything provided by the service employee. , they only agreed, the most important thing for them to settle the permit application they submitted, will have a different impact, because transparency is also an important element for achieving effective and efficient goals.

As well as in the theory of good governance in Tambunan $(2013,117)$ which explains information disclosure (accountability), accountability, responsibility (independency), independence (equality) and fairness (fairness) which are also key to achieving standard operating effective and efficient procedures when providing services to service users.

In addition to achieving effective and efficiency in implementing standard operating procedures, which also needs to be considered is the satisfaction of the customers themselves, if employees feel they have run standard operating procedures effectively and efficiently, but not perceived by service users, effective and efficient and not achieving maximum service. The satisfaction of service users is the culmination of maximum service and provides an overview to the public about the services provided, meaning that the desires of service users are also its function will provide convenience in every task even though it is in a different place with the same standard operating procedures.

\subsection{Consistent}

Consistency also involves the implementation that continues to run even if it is not following the conditions that make it difficult or even facilitate the service. This was also confirmed in the principles of standard operating procedures stated by Faozan's theory $(2009,17)$, namely:

"The principles of standard operating procedures are not intended to complicate the preparation of standard operating procedures but are intended to provide convenience for service providers in applying them. As a written instruction, standard operating 
procedures will be easily evaluated by the users so that they must be complete enough to be adhered to and quite simple to understand. It is this balance between complexity and simplicity that must be maintained so that standard operating procedures do not become mere guidance for service providers without giving service providers the benefit, or do not just become a display as a liability for orders from superiors.

This means that with the principles of the standard operating procedures, it is expected that the Investment Office and One-Stop Integrated Services staff will not only be fixated on applying but will also evaluate whether or not the procedures are available. Even better if there is a special team assigned to evaluate the existing procedure so that it becomes better. This is based on Tambunan's theory (2013.86) which states that:

"There are many events within the organization that show that there are no problems with the consistency of procedures with operational reasons. If there are still procedures that are still considered to slow down operational activities, what must be done is to immediately evaluate the procedure in question. Because procedures that are considered to slow down work are inappropriate and must be corrected according to the demands of the organization's needs. "

With the evaluation of standard operating procedures, employees will be consistent to implement it, because employees will more easily adjust their desires and need to existing standard operating procedures.

\subsection{Standards}

Setting standards of information on standard operating procedures for employees with their respective duties and functions has a positive impact on understanding the contents of the standard operating procedures themselves so that there is no dualism in understanding the same procedure. The service standard here is in the form of understanding the form of standard operating procedures in the Investment Office needed in implementing these standard operating procedures.

The consistency of employees in providing services based on standard operating procedures is the right step in improv and One-Stop Integrated Services. The form is a mixed technique. The following is an explanation of the form of standard operating procedures according to Tambunan (2013,309), namely:

a. Narrative techniques

The narrative technique is a technique that uses the power of narration and explanation through sentences that are following the rules of the correct language plus terms commonly used in organizations to explain the steps of activities in the organization, both related to operational and administrative activities.

b. Flow Chart Techniques

Flowchart techniques are specific techniques that are very well known in the development of information systems and procedures. Flow chart techniques use distinctive symbols, where each symbol will present activities, decisions, documents, reports, storage media, links and so on. The symbol of the current chart used is common and generally accepted. 


\section{c. Tabular techniques}

Tabular techniques or tabulations are very rarely used and displayed in the preparation and presentation of standard operating procedures. This technique is usually used to analyze activities in the process of compiling standard operating procedures, but that does not mean they cannot be displayed as procedures. Inactivity analysis, tabular techniques are used to calculate the effectiveness and efficiency of work processes. Potential steps exist in a standard operating procedure analyzed, including calculating the benefits and time needed to complete a step or activity.

d. Mixed Technique (Combined)

This technique is a varied combination of the three techniques described above, namely: narrative techniques, flow charts, and tabular. In practice, the combination of these three techniques is indeed widely used, especially so that the presentation of standard operating procedures is more easily understood by all involved and also interested.

It is called a mixed technique because in standard operating procedures in the Office of Investment and One-Stop Integrated Services contain narratives and explanations of existing procedures, load flowcharts, contain existing procedure tables. Therefore, understanding standard operating procedures with the same understanding will provide a standard measure of the service procedure itself. And no less important is the understanding that it will be easier to be informed to service users when providing services.

\subsection{Systematic}

Standard operating procedures are neatly arranged about explanation"Systematic characteristics are related to the appearance and explanation of standard operating procedures. A standard operating procedure, like a guideline or guideline, must be carried out in a clean, orderly and predictable system, and based on measures of success, failure, and clear and accountable risks. Systematic can be interpreted neatly and regularly; where this is an absolute requirement of an effective guideline to be used by an organization. "

In the systematic standard operating procedures, there are also terms and symbols in the flowchart that intend to shorten and provide certain codes so that they are easily understood by employees. However, the systematic standard operating procedures cannot be seen directly by service users, this is due to the non-disclosure or transparency of procedures contained in standard operating procedures by service users by showing or displaying them on a wall or designated place. As in the theory of good governance in Tambunan $(2013,117)$ to achieve what is desired there are basic principles, namely: transparency, accountability, responsibility, independence, equality, and fairness ( fairness).

\section{$5 \quad$ Conclusion and Discussion}

Based on the results of research at the Sumenep Regency Investment and Integrated Services One Door Service, it can be concluded that the importance of standard operating procedures in 
licensing services. Standard operating procedures are guidelines that must be used by employees in providing services to service users to achieve effective and efficient service conditions.

a. Effective (and efficient)

Lack of transparency and clarity of procedures for service users causes distrust of service users to existing procedures. So that this has an impact on the public's negative perception of services at the Sumenep Regency Investment and Integrated One-Stop Service.

b. Consistent

So far, the services at the Sumenep Regency Investment and Integrated One-Stop Service have not been matched by evaluations of standard operating procedures, so that the implementation of standard operating procedures is still not optimal. and explanations of activities, both in the form of descriptions of activities, procedures, time, costs, procedures, and so on. So that standard operating procedures can be said to have been structured systematically. Systematic is an absolute requirement of an effective guideline to be used by an organization. Tambunan's theory (2013.8) also states that the system is a very important component in implementing standard operating procedures, namely: ing service. Those who apply standard operating procedures despite different tasks and

c. Standards

Standard operating procedures are informed by the leadership widely to employees at the Sumenep Regency Investment and Integrated One-Stop Service Office so that employees can more easily understand and implement service procedures for service users.

d. Systematic

Standard operating procedures that have been neatly arranged and systematic about the explanations of activities, both in the form of descriptions of activities, time, costs, procedures, etc. provide convenience to employees in providing services to service users.

From the conclusions above, the researcher gave advice and input to the Sumenep Regency One-Stop Investment and Integrated Services Office about the importance of standard operating procedures in services to achieve maximum goals and services, namely:

a. Provision of information/transparency of operating procedures should not only be for service employees but also informed, explained and displayed to service users, because service users who know about procedures in standard operating procedures will be more confident and do not cause negative perceptions to the public.

b. The consistency of implementation must be encouraged, if there are procedures that are not appropriate in standard operating procedures, then an evaluation is needed by forming an evaluation team so that the standard operating procedures become clearer, more precise and good.

c. Guidance based services must be maintained because services that are always guided by standard operating procedures will be easier and more effective and efficient to achieve maximum service. 


\section{References}

[1] Arikunto Suharsimi, 2006, Research Procedure A Practice Approach to Revised Edition 6, Pt Rineka Cipta, Jakarta.

[2] Djam'an Satori, 2009, Qualitative Research Methodology, ALFABETA, Bandung

[3] Notoatmodjo, S, 2005, Research Methodology, Edition III, Rineka Cipta, Jakarta

[4] Sugiyono, 2003. Administrative Research Methods, Into Edition: 9. Alpha Beta Bandung.

[5] Sugiyono, 2016, Administrative Research Methods, Bandung, Alpha Beta CV. 